\title{
V. Extract of a report, on the means to be used for purifying the air in the apartments of sick persons, made to the society of medicine at Brussels
}

\section{J.B. Van Mons}

To cite this article: J.B. Van Mons (1799) V. Extract of a report, on the means to be used for purifying the air in the apartments of sick persons, made to the society of medicine at Brussels, Philosophical Magazine Series 1, 3:11, 258-260, DOI: 10.1080/14786449908676991

To link to this article: http://dx.doi.org/10.1080/14786449908676991

曲 Published online: 18 May 2009.

Submit your article to this journal $\pi$

Џll Article views: 2

Q View related articles $\longleftarrow$ 


\section{$\left[\begin{array}{lll}2 & 258\end{array}\right]$}

4. Exbrabl of a Report, on tbe Means to be ufed for purifying the Air in the Apartments of Sick Perfons, made to the Society of Medicine at Brufels. By J.B. VaN Mon.s.

$\mathrm{T}_{\mathrm{H}}$

I HE principal objeet of the author, in this Report, is to prove that it ought not invariably to be the aim of the phyfician to repair the lofs of a portion of the refpirable air in the atmofphere which furrounds the patient; fince difeafes may occur, fuch as thofe of a putrid and inftammatory nature, where an augmentation of the unrefpirable part may, be beneficial. In fuch difeafes, if air of the common ftandard be refpired, the patient is furnifhed with fuch a portion of oxygen as, by increafing animal heat and accelerating circulation, muft naturally increafe the fever, inflammation and putrefaction, or decompofition of the blood and other humours: A lowered atmofphere, which in health is improper for refpiration, muft in thefe ftates prove falutary, as, by affording lefs oxygen to the fyftem, it will abate inflammation, check the putrefaction, and diminifh other bad fymptoms, producing the good effect of what are called cooling medicines. Thefe principles are confirmed beyond a doubt by daily experience *.

"It is," fays this author, "to the falutary. effect produced by diffuing through the atmofphere a new portion of unrefpirable and of diminifhing the refpirable air that fumigations have been fo long indebted for their being employed as correctors of corrupted air, while thofe who prefcribed them often did fo on a very contrary fuppofition.

"In general I have found the air in the apartments of fick perfons to confift of abundance of carbonic acid gas, hydrogen gas, oxygen gas, and azotic gas; fometimes of a

* No facts of this kind are knowa in England; and from the experience of Dr. Thornton and-others, it would feen, that a fiper-oxygenated air is highly beneficinl in putrid difexies, although it be inimical to thofe of an inflammatory nature. EDIT. 
little ammoniacal gas, and a peculiar emanation called contagious miafm, which appears to be a particular combination of hydrogenous carbonic acid gas, holding in folution animal fluials as yet little known. Hydrogen gas almoft always holds in folution pure carbon, phofphorus, \&c. from which arifes the fmell of thefe gafes, often fo difagreeable. Carbonic acid gas would form a much more confiderable part of the atmofphere which furrounds fick perfons, were not this gas continually neutralifed and rendered concrete by the ammonia, which is formed and evolved in all difeafes where animal fubftances containing azot are decompofed. It may readily be perceived into what contradiction thofe have fallen who fuppofe air to contain at the fame time carbonic and ammoniacal gas. The abfurdity of expofing in the apartments of the fick, veffels filled with quick-lime, muft alfo be obvious; the inconvenience of which, in all cafes, is to leave in a difengaged ftate, or to resturn to the air, the ammoniacal gas; the carbonic acid gas, which would otherwife neutralife it, being taken up by the ftronger affinity exerted upon it by the lime; and, in fome cafes, to take away an unrefpirable gas, the prefence of which wonld be beneficial.

"I have afcertained that in a ftate of health we form by refpiration more water, and in a ftate of difeafe more carbonic acid. The carbon feems, at a certain temperature, to exercife on the oxygen a ftronger attraction than the hydrogen can in the fame temperature. Among the principal means for purifying infected air I clafs vaporifed water, which incommodes the patient very little, and takes putrid emanations out of circulation better than the muriatic and acetous acids, or than fpirits, being a better folvent than thefe liquids. When the air is furcharged with ammonia, $I$ would rather let loofe into it the carbonic acid gas than the acetous or any other acid. The cafe in which C. Guyton employed with fo much fuccefs the muriatic acid vapours 
was totally different from thofe which have been the objects of my refearches.

The fulphurous acid gas would be ufeful in fome cafes to decompofe miafmata, by giving up to them a portion of its oxygen; but it leaves behind it an oxyd of fulphur, the fmell of which is extremely offenfive: the oxygenated muriatic acid gas ought therefore to be preferred.

The gafes which in my opinion ought to be employed for augmenting the portion of unrefpirable air, are the carbonic acid gas and hydrogen gas. The firt ought to be made to pafs through water, and the fecond through oil. By thefe means you free the carbonic acid gas from that portion of the acid employed to difengage it from the carbonat ufed, which it carries along with it; and you precipitate from the hydrogen gas the carbon it holds in folution. The oil, after being ufed fome time for this purpole, is found quite black, and converted into empyreumatic or carbonated oil.

VI. Simple and Eafy Metbod of Cleaning and Wbitening Prints or Engravings, By M. Fав в воN I. From Annali di Chimica, by Brugnatelu. Vol. XIV.

$\mathrm{T}$ HE methods formerly employed for cleaning engravings confifted in wafhing them in pure water, or a weak lixivium of pot-afh, or in expofing them a very long time to the dew. Aquafortis has alfo been fometimes employed. Leys, however, together with the dirt and filth, carried away part of the colour of the engraving, and aquafortis attacked the vegetable fibre of which the paper of the print was compofed.

Since the difcovery of the oxygenated muriatic acid by Scheele, and the application of its properties, by Berthollet, to the bleaching of cloth, trials have been made of it alfo for whitening prints and engravings ; and Chaptal's experiments on this fubject were attended with the beft fuccefs *.

* For Chaptal's procefs fee Phil. Mag. Vol. 11. p. 28. 